\title{
A Location Based Time and Attendance System
}

\author{
Mohammad Salah Uddin, Member, IACSIT, S. M. Allayear, N. C. Das, and F. A. Talukder
}

\begin{abstract}
Time and Attendance System provides many benefits to organizations. It enables an employer to have full control of all employees working hours. It helps control labour costs by reducing over-payments, which are often caused by transcription error, interpretation error and intentional error. Manual processes are also eliminated as well as the staff needed to maintain them. It is often difficult to comply with labour regulation, but a time and attendance system is invaluable for ensuring compliance with labour regulations regarding proof of attendance.

Every Organization has a specific location, which is determine by the GPS. The location of an employee can be determined by GPS device (Mobile Phone, GPS watch or GPS enabled device etc.). If the location of an employee and the location of organization is same (Approx.), then it should be said that, the employee is in the office. This paper use location as a proof of attendance and proposed a new time and attendance system based on location.
\end{abstract}

Index Terms - Location-based service, GPS, locationing, time and attendance system, android, apps.

\section{INTRODUCTION}

Now a days, two types of attendance system are available, i) Manual and ii) Automated. Manual time and attendance systems use paper time cards and time sheets that employees fill out and managers oversee for accuracy. However, time and attendance information is subject to human error when various employees such as workers, managers, and payroll administrators all perform tasks that involve recording the numbers. Employees punch in and out when they arrive at work, go to lunch, take a break, or leave for the day.

Generally, managers must add up the minutes and hours worked, using each employee's time card, and fill in a time sheet indicating hours worked for the week. Managers also spend time filling out attendance records based on whether employees punched the clock. A lot of man hours go into calculating time and attendance when using a manual system [1].

Automated time and attendance systems can use electronic tags, bar-code badges, magnetic stripe cards, biometrics (hand, fingerprint, or facial), and touch screens [2] in place of paper cards which employees touch or swipe to identify themselves and record their working hours as they enter or leave the work area. The recorded information is then ideally automatically transferred to a computer for processing although some systems require an operator to physically transfer data from the clocking point to the computer using a portable memory device. The computer may then be

Manuscript received July 2, 2013; revised September 10, 2013.

The authors are with the Department of Computer Science and Engineering, East West University, Dhaka, Bangladesh (e-mail: akash.bangla@gmail.com). employed to perform all the necessary calculations to generate employee time-sheets which are used to calculate the employees' wages. An automated system reduces the risk of errors that are common in a manual system, and allows the workforce to be more productive instead of wasting time on tedious administrative tasks. [3] This paper proposed an Automated Time and Attendance System that use Location instead of traditional methods.

\section{RELATED WORK}

In this section, we review some related technologies and previous works on the topic of location based application. Geolocationing is the first step to providing location based services. The most widely used locationing technologies are GPS, Wi-Fi, Cellular, Bluetooth, Infrared, and Radio Frequency Identification (RFID). Researchers work on these technologies for improving the services, such as accuracy and environmental effects. Using a single locationing technology, improve the locationing accuracy of RFID by developing reference tags in the field. Locationing accuracy can also be improved by combining two or more locationing technologies [4].

A number of related works exist on the application of different methods and principles to effectively monitor the attendance of individual. In [5], an embedded computer based lecture attendance management system was proposed. The system provides an improvised electronic card and card reader serially interfaced to the digital computer system.

Attendance Management has also been carried out using attendance software that uses passwords for authentication. The authors in [6] designed and implemented a system that authenticates the user based on passwords, this type of system allows for impersonation since the password can be shared or tampered with. Passwords could also be forgotten at times thereby preventing the user from accessing the system.

Other attendance solutions are RFID-based student attendance system. Problem with RFID [7] based systems is that individuals have to carry RFID cards and also the RFID detectors are needed to be installed [8].

The application of attendance system using biometric system has been demonstrated by Simao, Fonseca and Santos [9] with integration of wireless communications. However, the weaknesses of the system has been discovered by Zhang et al. [10] by introducing palm-print which developed an attendance system to record the employee attendance. Meanwhile a similar project has been implemented by Kardry and Smaili [11] which applied wireless Iris recognition attendance management system. In Bio-metric identification security is the main concern; if we lost our biometric identification database then our biometric 
identification is totally compromised.

\section{The Proposed LocAtion BASED TIME AND ATTENDANCE SYSTEM}

\section{A. System Overview}

The system replaces the traditional Identification Card by a mobile application. The application was installed on users mobile. A unique user ID and location (GPS coordinate) was associated with the application. A time and attendance software was installed on workstation for process the data receive from user mobile and store the information (time, entry and leaving) to the Database. The basic block diagram is shown in Fig. 1.

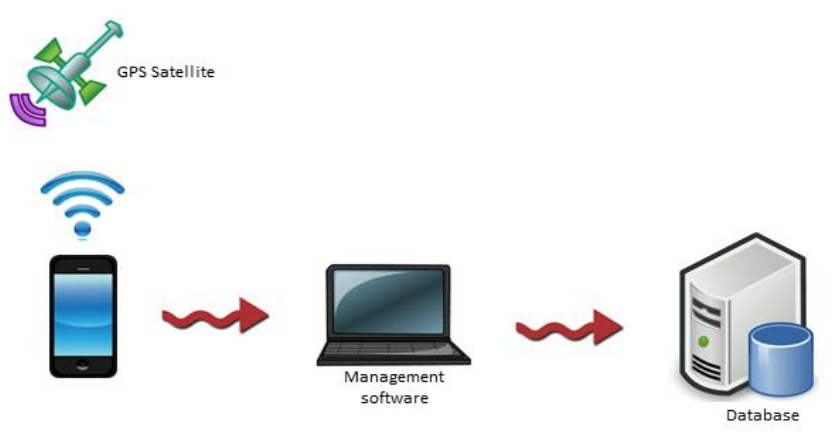

Fig. 1. Basic block diagram of location-based time and attendance system.

\section{B. System Architecture}

The schematic diagram of our location-based time and attendance system is shown in Fig. 2. This system employs four hardware and software components, described as follows. The smartphone is built-in with a GPS receiver, which can receive radio signals from GPS satellites, respectively. Google maps API (Application Programming Interface) is used here for finding personal meaningful location; based on the GPS readings, the application can perform geo-locationing to estimate the current location of the user.

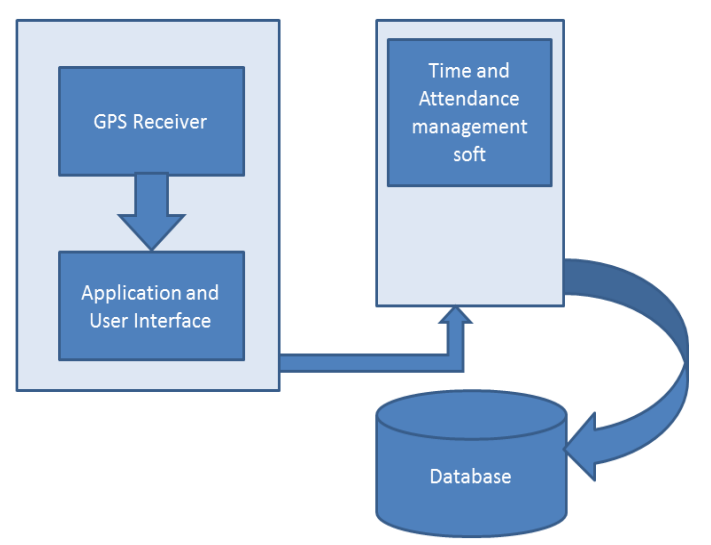

Fig. 2. Schematic diagram of the proposed location-based time and attendance system.

Then the application sends the location and user Id to Time and Attendance Management Software for further process. After processing the data the management software store the information to Database.

\section{Flow of Operation}

Since location-based time and attendance system uses Mobile Application and a time and attendance management software for processing data. So, the flows of operation of the Mobile application are:-

1) Determine the location using GPS

2) Check the location with pre-stored (office/workspace) location

3) Encrypts user ID and Location

4) Send information to the system

Fig. 3 shows the flows of operation of Mobile application. First, the application figure out the location using GPS. Then, its check the location with pre stored (office/workspace) location, if location matched then the application makes a data packet containing user ID and location, encrypt them and send it to the management system.

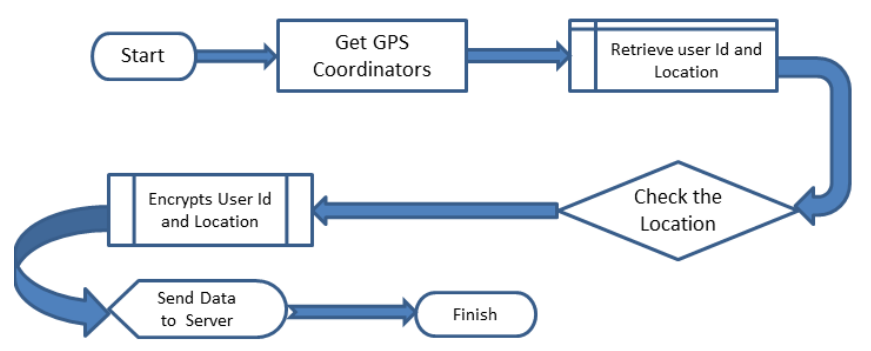

Fig. 3. Flows of operations for mobile application.

The flows of operation of the management software are:-

1) Receive data from Mobile application

2) Decrypts the data

3) Retrieve user ID from Database

4) User Identification

5) Store the information.

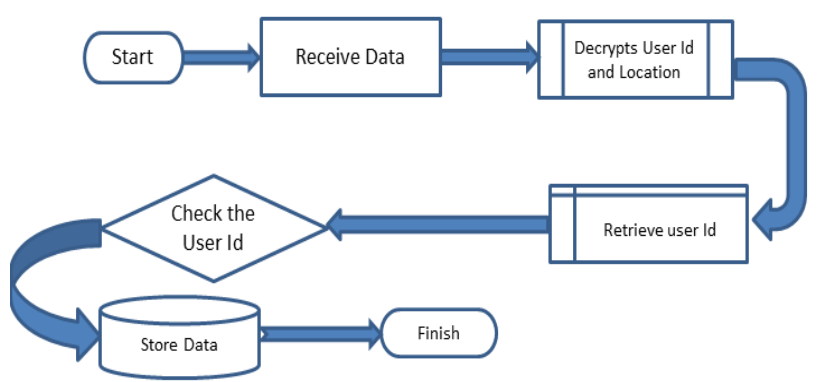

Fig. 4. Flows of operation for Time and Attendance Management software.

Fig. 4 shows the flows of operation of the management system software. The software first receives the information from the mobile application. Then its decrypt the information and check for validation. After passing the validation steps it store the information to the database according to the user ID.

\section{IMPLEMENTATION}

Due to the shortest of time the proposed model is not totally completed. The hardware requirements are Android [12] \& GPS [13] enable phone or tabs or any device that is used as a user identification tools. A time and Attendance Management Software which interacts with user device is 
required. The software is also connected with Database for storing data. There are several tools/ methods are available for developing time and attendance management software such as .Net, java, php etc. Eclipse IDE [14] with Android Development Tools will be used for developing the android (Mobile) application.

\section{COMPARISON}

Table I shows the comparison between traditional Attendance System and The proposed System.

TABLE I: A COMPARISON BETWEEN PROPOSED MODEL AND TRADITIONAL

\begin{tabular}{lcc} 
& SYSTEM & \\
\hline \hline & TRADITIONAL & PROPOSED \\
Sost & SYSTEM & SYSTEM \\
Maintenance & Requires skilled people & Anyone can \\
Installation & Not so easy & Very easy \\
Fully & Not fully automated, & Fully automated \\
Automated & $\begin{array}{c}\text { you may touch or } \\
\text { punch something }\end{array}$ & \\
& & \\
\hline \hline
\end{tabular}

\section{CONCLUSION}

This paper introduce a Location based Time and Attendance System, that use Location as the key of attendance. The coordinates of an organization and an employee can be determined by the help of GPS device, both coordinate are same means employee is present in the organization. We currently developing the system for Android enable smartphones/ Tabs. In future we extend our system for iPhones and other mobile phones.

\section{ACKNOWLEDGMENT}

This paper is made possible through the help and support from everyone, including: parents, teachers, family, and friends.

Especially, please allow us to dedicate our acknowledgment to Dr. Shamim H Ripon, Associate Professor of East West University, Aftabnagar, Dhaka, Bangladesh for his most support and encouragement.

\section{REFERENCES} [1] Time and Attendance. [Online]. Available:
http://www.en.wikipedia.org

[2] A Short Course on Fundamentals of Touch Technologies and Applications, Geoff Walker Principal Analyst IMS Research, 2010.

[3] Automated Time and Attendance System. [Online]. Available: http://www.gatekeepersolutions.com

[4] C. Y. Lin and M. T. Hung, A Location-Based Personal Task Reminder for Mobile Users, Springer Verlag, London, 2013.

[5] O. Shoewu, O. M. Olaniyi, and A. Lawson. "Embedded computer-Based lecture attendance management system," African Journal of Computing and ICT, vol. 4, no. 3, pp. 27-36, 2011.

[6] K. Cheng, L. Xiang, T. Hirota, and K. Ushijimaa, "Effective teaching for large classes with rental PCs by web system WTS," in Proc. Data Engineering Workshop (DEWS2005), 1D - d3 (in Japanese), 2005.

[7] O. Shoewu, and O. Badejo, "Radio frequency identification technology: Development, application and security Issues," Pacific Journal of Science and Technology, vol. 7, no. 2, pp. 144-152, 2006.

[8] S. Pankanti, S. Prabhakar, and A. K. Jain, "On the individuality of fingerprints," IEEE Trans. on Pattern Analysis and Machine Intelligence, vol. 24, no. 8, 2002.
[9] P. Simao, J. Fonseca, and V. Santos, "Time attendance system with multistation and wireless communications," in Proc. IEEE International Symposium on Consumer Electronics, 2008, pp. 1-4.

[10] M. Wong et al., "Online Palmprint Identification", IEEE Trans. on Pattern Analysis and Machine Intelligence, vol. 25, no. 9, pp. 1041-1050, Sept 2003.

[11] S. Kadry and K. Smaili, "A Design and Implementation of a Wireless Iris Recognition Attendance Management System," Information Technology and Control Kaunas, Techbologija, vol. 36, no. 3, pp. 323-329, 2007.

[12] J. Chen, An Introduction to Android, 2008.

[13] C. Rizos, Introduction to GPS, University of New South Wales, 1999.

[14] M. Dexter, Eclipse and Java for Total Beginners Companion Tutorial Document, Bebag, 2011.

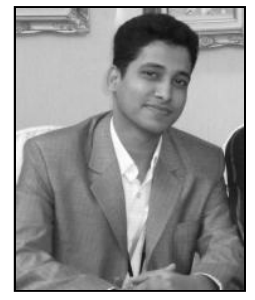

Mohammad Salah Uddin is a lecturer in the Department of Computer science and Engineering, Central Women's University, Dhaka, Bangladesh. $\mathrm{He}$ is a member of IACSIT and Software Engineering and Formal Method Research Group of East West University. He received his B.Sc in Computer Science and Engineering from East West University, Dhaka, Bangladesh in 2012. He passed his Higher Secondary Certificate (H.S.C) and Secondary School Certificate (S.S.C) form Dania College, Dhaka, Bangladesh in 2004 and Shajahanpur Railway Colony Govt. High School, Dhaka, Bangladesh in 2002. He published several journal and international conference paper from his research work.

His research interest includes web service composition, semantic web service, knowledge representation, mobile apps, location based service, software engineering, software product line, modeling and verification, artificial intelligence, digital image processing, etc.

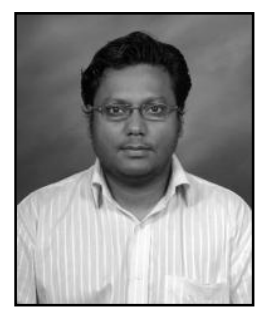

Shaikh Muhammad Allayear is a full time faculty member of Department of Computer Science and Engineering (CSE), East West University, Dhaka, Bangladesh holding the position of Assistant Professor. He has completed his Ph.D. in Computer Science \& Engineering from Anyang University,South Korea in 2009. From the same university, he has completed his M.Sc in Computer Science \& Engineering in 2004. Before joining here, he was a part time lecturer of Department of Computer Science \& Engineering, Anyang University, South Korea. He has 8 years research experience from well reputed research company in Korea.

His research interest includes network storage, internet computing, parallel \& distributed system, high performance computing, mobile computing, information security, etc.

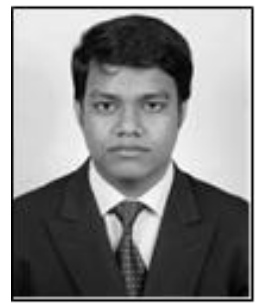

Nakul Chandra Das completed his B.Sc in Computer Science and Engineering from East West University, Dhaka, Bangladesh in 2013. He is a member of Software Engineering and Formal Method Research Group, East West University. He is interested in: mobile application, semantic web service, software engineering, and software product line.

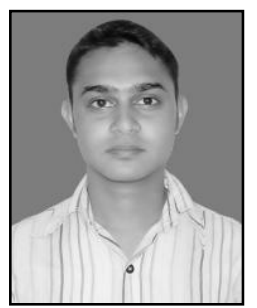

Firoz Ahmed Talukder was born in Mymensingh, Bangladesh. He completed his B.Sc in Computer Science and Engineering form East West University, Dhaka, Bangladesh 2013. He passed his Higher Secondary Certificate (H.S.C.) from Nasirabad College, Mymensingh, Bangladesh in 2007 and Secondary School Certificate (S.S.C.) from Mukul Niketon High School, Mymensingh, Bangladesh in 2005. He is interested in: mobile applications, web aapplications, and games development. 